\title{
Globalisation and international compatibility - a challenge to learning within the context of application
}

\author{
J S Wessels \\ University of South Africa
}

\begin{abstract}
The contexts of institutions for higher education are in flux with consequent learning challenges. One of these challenges is that of globalisation and the need for international compatibility. Another challenge is that Mode 2 learning programmes, material and methods need to be relevant to the specific context in which they are applied. The purpose of this article is therefore to determine whether it is possible for offerings of learning to be relevant to the country-specific context of learners and simultaneously prepare learners to be internationally competitive and globally compatible. This article argues that learning that has occurred in a country-specific context does not necessarily equip learners with only country-specific knowledge and skills. Problems that are investigated may be countryspecific, but the transferrable knowledge, skills and competencies that are produced from reflection on a problem in one context can be used to solve similar problems in other contexts.
\end{abstract}

\section{INTRODUCTION}

$\mathrm{S}^{\mathrm{o}}$ outh African institutions for higher education find themselves in a changing and challenging environment. Worldwide, the contexts of institutions for higher education are in flux with consequent challenges for the way these institutions enhance learning.

One such contextual challenge is that globalisation and the need for international compatibility increasingly have became the reality faced by institutions of higher education. This reality is characterised by an expansion of liaison and collaboration between institutions of higher learning from various countries and their offerings to learners in other countries.

Moreover, a paradigm shift has occurred in the global field of higher learning with implications for the nature of international liaison and collaboration as well as for learning programmes in all fields. One direct implication of the specific nature of knowledge within this new paradigm has been that learning programmes, material and methods need to be relevant to the specific context in which they are applied.

This new reality of globalisation and international competitiveness, combined with the new paradigm which demands greater contextual relevance of learning programmes, poses distinct challenges for the providers of learning. The purpose of this article is therefore to determine whether it is possible for offerings of learning (and in the case of distance learning, the learning material) to be relevant to the country-specific context of learners and simultaneously prepare learners to be internationally competitive and globally compatible.

\section{A PARADIGM SHIFT IN THE FIELD OF LEARNING}

An overview of the literature on higher learning indicates that fundamental changes have occurred in the field during the past decade (Barr \& Tagg 1995; Dahlin 1999; Gibbons 1998; Killen \& Spady 1999; Levinger 1996; Marzano, Pickering \& McTighe 1993; Schn 1995; Vermunt 1996; Zuber-Skerritt 1993, 1995; Wessels 2001). Although not all researchers have ventured so far as to identify these changes as part of a paradigm shift, an analysis of the distinct characteristics of these changes shows that it may indeed not be too daring to use the term "paradigm shift" in this regard (Wessels 2000, 2001). Although many researchers have published on this topic, for the purpose of the main argumentation of this article, I will refer to only one of these publications.

In 1998, Michael Gibbons, Secretary-General of the Association of Commonwealth Universities, distinguished two types of knowledge, namely Mode 1 knowledge and Mode 2 knowledge (Gibbons 
1998:4). According to this distinction, Mode 1 knowledge is a model of knowledge production that has a disciplinary basis while Mode 2 knowledge is a shift to knowledge configuration through interaction with a variety of knowledge producers outside the traditional disciplinary boundaries (Gibbons 1998:i). A characteristic of Mode 2 knowledge, according to Gibbons, is its "dynamics of relevance" (Gibbons 1998:10), referring inter alia to the production of knowledge in the context of application (Gibbons 1998:6, 58). This characteristic of Mode 2 knowledge forms the first premise of the main argument of this article, namely that "learning within Mode 2 should be relevant to the context of the learners".

According to Gibbons this "dynamics of relevance" must be related to globalisation and the strengthening of international competitiveness. This brings us to the second premise of this article, namely that "learning within Mode 2 should be internationally competitive and globally applicable". With these two premises in mind, the question that directs this article arises, namely whether offerings of learning which are to be relevant to a country-specific context of learning can simultaneously prepare learners to be internationally competitive and globally compatible.

\section{LEARNING IN THE CONTEXT OF APPLICATION: RELEVANT OFFERINGS OF LEARNING}

Why is it necessary for learning to occur within the context of application? One reason that Gibbons (1998:6) offers is its usefulness to someone, whether in industry, government, or society more generally. Implicit in lifelong learning is the need for student discovery and construction of knowledge (Barr \& Tagg 1995) to be concentrated on real issues and problems in authentic conditions (Zuber-Skerritt 1993:46) in order to solve specific mutual problems. In order for the learning that occurred to be useful, it makes sense that learning material and methods of tuition need to enhance relevant learning.

Another and perhaps equally important perspective on the necessity of contextualised learning is the enhancement of the understanding of learners. In research conducted in Sweden it has been found that understanding requires activity relating new information to previous knowledge, connecting facts and weaving bits of knowledge together (Dahlin 1999:202). This research confirms that learning within the context of application, in other words a real life experience, illuminates what a learner has previously read but not understood (Dahlin 1998:203). The research results also indicate that the feeling of personal significance is seen as the central factor for the development of understanding (Dahlin 1998:203). It is for that reason that actively engaging with the learning material and discussing it with peers, in other words doing things with the material being learnt, play such an important part in the learning process (Dahlin 1999:203).

In the process of assessing teaching or learning material and methods, one may ask whether material and methods succeed in making the learning content relevant to the specific contexts of the learner. A few criteria have been identified in earlier research to determine the contextual relevancy of learning material (Wessels 2001a:223). For the purpose of this argument, three of these criteria are crucial, namely whether material and methods -

- make provision for learning experiences essential to successful performance in the various life roles of the learner

- connect to learners' own experiences and reality to create personal relevancy

- have a problem-based approach, instead of discipline-based approach.

In order to find some answers to these questions, the results of an evaluation of the learning material aimed at first year learners in Public Administration at the University of South Africa (Unisa) will be used. This evaluation occurred in two stages: firstly a survey of learners during the first year of implementation of the learning material (1998) and secondly a qualitative assessment by an external panel (1999). For the purpose of this article we will use the results applicable to one study guide, namely Study Guide 1. The results will be discussed under the headings "various life roles", "personal relevancy", and "problem-based approach".

\section{Various life roles}

According to Killen and Spady (2000:204) one can identify at least five life roles for learners, namely career, entrepreneurial, civic, personal and learner. Levinger (1996) refers to this holistic approach as developing human capacity to enable individuals to perform tasks which are necessary to survive and prosper. In order to be relevant, it can be expected that curriculum design and implementation will ensure that learners systematically develop the essential knowledge and skills needed to understand and carry out these life roles (Killen \& Spady 2000:205). By covering all life roles of a learner, one can expect that offerings of learning will not fall into the trap of the traditional vocational education which too often provided training that, by virtue of its over-specificity, soon became obsolete (Levinger 1996). It should also make it possible to avoid the pitfall of an overly academic approach which provides only in the academic needs of learners.

The selected study guide has been shown to be 
written predominantly from a citizen perspective bearing the learners' civic life role in mind (Wessels $2001 \mathrm{~b}$ ). That is why topical issues (such as the increased incidence of Aids) are used to put learning activities (such as activities relating to the influence of society and its milieu on the provision of public services) within the context of the daily civil experiences of learners. In other words, real-life experiences are used to enhance understanding and to promote "deep learning".

With regard to their life-role performance in a career or occupation, $91 \%$ of the respondents in the 1998 survey held the opinion that the study package took their "present or future occupation into consideration" (Survey 1998: Question 23), 89\% felt that the study package equipped them for their "present or future occupation" (Survey 1998: Question 24) while $87 \%$ were convinced of the relevancy of the study package for their present or future occupations (Survey 1998: Question 25)

The relevancy of the learning material to the contexts of the learners was confirmed by the fact that $92 \%$ of the respondents held the opinion that the study guide was "mostly applicable to life" as they experience it (Survey 1998: Question 32) and succeeded in retaining their interest (Survey 1998: Question 33). These assessments by the students were supported by the external panellists who, with one exception, believed that the study guide was relevant to vocational, professional and social requirements (Panel 1999: Question 7.3). From the above, one can safely conclude that the learning process facilitated by this study guide was experienced by the learners and the external panel as relevant to life in general and to their present or future professions or occupations in particular.

With regard to its relevancy to the learners' life roles as learners, an assessment of all 42 activities and five self-evaluation sections (SEs) in the study guide revealed that the particular study guide was directly relevant to effectively carrying out learner life-role functions such as reading, summarising, critical thinking and writing.

Taking into consideration the research results on the extent to which the learning material facilitates learning within the various life roles, one can safely conclude that this particular study guide does make provision for facilitating learning that will be needed to carry out the various life-role functions.

\section{Personal relevancy}

A worldwide movement in institutions for higher education from purely academic education to professional and vocational education coincides with what Zuber-Skerritt (1993:53) calls a shift from classroom to practice - in other words, control over the learning process is shifting from universities (the typical providers) to the learners (typical receivers). As control over the learning process shifts from the lecturer to the learner, one can expect an increase in the personal relevancy that learning has for learners.

With regard to the analysed study guide, no less that $64,6 \%$ of respondents prefer the contents of their learning material to be related to their personal experiences and emotions (Survey 1998: Question 2 ). In other words, they want their learning material to be relevant and meaningful to their personal circumstances.

Research by Vermunt (1996:46) shows the possibility of a progression of learning styles in that a learner's style often develops from external to internal regulation. The more experienced and skilled learners become in a specific learning style, the more they learn under internal control. It is thus possible that a learner can switch from an externally regulated, reproduction-directed learning style to an internally regulated (self-directed) meaning-directed style. The personal commitment to learning associated with self-directed learning then forms the basis of what Dahlin (1999:206) calls "deep learning".

Control over the learning process is determined, among other factors, by learners' acceptance of responsibility for their own success as well as their freedom to participate in the learning process and to form their own opinions on critical issues. The survey shows that $91 \%$ of the learners felt co-responsible for their success in passing the course (Survey 1998: Question 15). This feeling of responsibility is reflected in the fact that nearly $74 \%$ did not agree that their success depends entirely on their lecturers (Survey 1998: Question 16). Furthermore, 94\% of the learners agreed that the study guide encouraged student participation (Survey 1998: Question 58) and 87\% agreed that the study guide equipped them to form their own opinions on issues and to defend such opinions (Survey 1998: Question 69).

It has been shown from the aforementioned that the learners regarded the study guide as being engaged in an effort to shift control of the learning process over to the learners. This shift implies an increase in the level of relevancy of the learning material for individual learners personally.

\section{Problem-based approach}

The external panel's evaluation concentrated mainly on relevancy to Public Administration as an academic field of study. Members of the external evaluation panel predominantly held the view that the study guide served (adequately to well) as a sound introduction to the subject of Public Administration 
(Panel 1999: Question 2.1). The detailed evaluation of the study guide by the panel (Panel 1999: Questions 4.1-4.15) revealed that the panellists believed that the study guide should be disciplinebased, instead of problem-based (see specifically the answers to Question 4.4). It seems that at least some of the panellists were concerned that the study guide did not have a sufficient theoretic base (Panel 1999: Questions $7.5 \&$ \&.6). These responses actually confirm that the study material has a more problembased approach than a discipline-based approach.

This section of the article has shown that learning material that is relevant to the context of its learners will increase the usefulness and understandability of the learned knowledge and skills for those learners. Furthermore, the relevancy of the particular study guide is shown through its -

- facilitation of learning experiences essential to successful performance in the various life roles of the learner

- connection to learners' own experiences and reality to create personal relevancy

- problem-based approach, instead of disciplinebased approach.

\section{GLOBALISATION AND INTERNATIONAL COLLABORATION: REOUIREMENTS FOR OFFERINGS OF LEARNING}

This brings us to the second premise of this article, namely that "learning within Mode 2 is globally applicable and internationally competitive". One may ask whether this is not what higher education and specifically science have always been: possibly the most international of human activities.

Various scholars have recently commented on increasing global competition with special emphasis on competitiveness and flexibility (Edwards 1997:30 31). This trend has been recognised by, inter alia, the National Commission of Inquiry into Higher Education in Great Britain who stated in their report on National Consultation that higher education "has to recognize a globalisation of the economy, knowledge and culture" (National Commission 1997). Levinger (1996) refers in this regard to a process of global restructuring that is underway as technology alters the ways in which people are expected to work for those who employ them.

One of the results of the process of globalisation seems to be that workers have become what Levinger (1996) calls "planet dwellers" who travel from one job-opportunity to another all over the world. In fact, a skill-poor labour pool seems to encourage global companies to search transnationally for employees with suitable skills and qualifications. Within the South African context one may ask whether offerings of learning succeed in equipping learners with those knowledge and skills that will enable them to compete for jobs at global companies? Furthermore, many countries and firms have acquired the capacity to use research and scientific knowledge produced elsewhere (Gibbons 1998:20-21). Do South African offerings of learning equip learners with the knowledge and skills necessary to apply scientific knowledge produced elsewhere as solutions for countryspecific problems?

Whereas globalisation may be to the advantage of the knowledgeable and skilled workers, it is probably a threat to "the poor, the marginalized, and those who daily struggle to meet their basic human needs" (Levinger 1996). For those people, the era of globalisation means greater insecurity, unemployment, inequality, and poverty (Edwards 1997:40). In fact, the absolute number of the world's people living in absolute poverty has increased to more than a billion (Stewart 1999:103). Learning programmes should therefore be accessible to those marginalised learners to improve their competitiveness in the local and global markets for skilled labour, at least to earn a living.

According to Gibbons (1998:30) one of the results of the globalisation of the economy and the pressures of international competition is the dissolving of boundaries between nations, institutions and disciplines. This poses special challenges to institutions of higher learning with regard to -

- the production of scientific knowledge and skills and

- a share in the global market of learning institutions.

Production of scientific knowledge and skills, the first of these challenges to institutions of higher learning, is certainly the core function of universities. It is commonly accepted that there is a strong correlation between a country's ability to produce and consume scientific knowledge and skills, on the one hand, and its economic performance on the other. Gibbons (1998:22) observes that the "access to knowledge and expertise, re-configuring it in novel ways, and offering it for sale are becoming specialised business functions".

Specialised knowledge seems to be a crucial source for adding value, even in mass-produced products. Furthermore, the ability to innovate continuously seems to be crucial to long-term performance. Specialised knowledge is the source of a "created" comparative advantage and the need for ongoing innovation drives forward changes in terms of products. Competition is concerned with technology and with knowledge and skills. Universities, as the primary technology and knowledge producers in most societies, play a key role in the competitive process (Gibbons 1998:24). One hesitates to ask whether 
universities can adapt to be able to play a more participatory role in the production of scientific knowledge with a global impact.

Levinger (1996), however, is quite pragmatic about knowledge production. She sees it primarily as a means to enable people to earn a living: to produce new knowledge on a global scale, learners need to be flexible, adaptable, collaborative and problem-solving.

Levinger (1996) proposes the creation of a new science, partagogy, which has as its primary focus helping individuals to develop the skills and knowledge they need "to access available participation opportunities and create new ones over the course of their lifespans". Partagogy is a science of learning specifically to foster human capacity development opportunities (Levinger 1996). It views human capacity development as a twofold process which involves augmenting the degree to which an individual (1) accesses extant participation opportunities: (2) contributes to the creation of new opportunities.

The second challenge to institutions of higher learning is the competition for a share in the global market of learning institutions. It has become common practice for many South African learners to enrol at foreign learning institutions and for foreign students to enrol at South African institutions. In fact, South African universities are in growing competition with these foreign institutions for student numbers. However, there is not only competition but also collaboration. An example of this are the cooperative agreements reached between South African universities and foreign institutions such as the Open University of the United Kingdom, the Open University of the Netherlands and Thomas Edison State College in the USA (Melck 2000).

To summarise, institutions of higher learning in South Africa are by default part of the global community of learning institutions. Their participation in this community immediately places them in a competing position with other institutions. As more and more learners are starting to compare similar learning programmes offered by different institutions, it becomes crucial that South African institutions of higher learning are indeed able to offer learning programmes that compete favourably with similar programmes in the global market with regard to cost, transferable knowledge, skills and competencies.

Which determinants will help to establish whether offerings of higher learning, such as the selected study guide that we have analysed, indeed prepare learners to be globally compatible and internationally competitive? The following are suggestions of competencies that may be necessary for learners to be competitive in the global labour market in order to, at least, earn a living:
- To re-configure and apply scientific knowledge produced elsewhere as solutions for countryspecific problems

- To be an innovative problem-solver

- To access participation opportunities and to create new ones

- To play a participatory role in global knowledge production

- To be flexible and adaptable.

The crucial question is: Does the learning material that has been shown to be relevant to the context of the particular group of learners simultaneously enhance those competencies that will enable learners to be competitive in the global labour market?

The same evaluation study that has shown the particular study guide to be relevant to the context of its learners, has shown that at least $59 \%$ of all the learning and self-evaluation activities in the study guide assist learners to apply theory to practical situations (Survey 1998). This is a competency necessary for learners to re-configure and apply scientific knowledge produced elsewhere as solutions for country-specific problems.

In order to be innovative problem-solvers, it appears to be crucial for learners to be independent thinkers. In this regard the study guide has been shown to be successful as nearly $93 \%$ of the 965 respondents believed that the study guide gave them the opportunity to think for themselves (Survey 1998: Question 63) while $87 \%$ believed that the study guide equipped them to form their own opinions on issues and to defend their opinions (Survey 1998: Question 69).

Although competencies such as accessing participation opportunities and creating new ones, playing a participatory role in global knowledge production, and being flexible and adaptable, are not facilitated explicitly in this specific study guide, it does not mean that they are neglected at all. This particular study guide is part of an introductory module. Subsequent modules within this specific programme address such competencies, and learners come to understand the meaning and nature of globalisation and to recognise the implications of globalisation on both government, the private sector and the individual (Theunissen 1999:45-50).

Having concluded that it is necessary for offerings of learning to prepare learners (be they "planet-dwellers" or the marginalised poor) to be competitive in the global labour market, it has been shown that the selected study guide, however limited it may be, does facilitate the acquisition of innovative problem-solving skills as well as the ability to apply global theoretical knowledge as solutions for country-specific problems. 


\section{CONCLUSION}

As a point of departure, this article has shown that a global paradigm shift has occurred in the field of learning. The essence of the new paradigm is its emphasis on the production of knowledge in the context of application, referred to as the dynamics of relevance. This article has demonstrated that learning material that is relevant to the context of its learners will enhance the usefulness and understandability of the learned knowledge and skills. Related to the dynamics of relevance, the necessity to prepare learners to be competitive and compatible in the global labour market has also been confirmed.

Furthermore, evaluation of the selected study guide has shown that it facilitates learning within a countryspecific context of application by enhancing the ability of learners to reconfigure and apply knowledge to their specific contexts. To some extent it also equips learners with the knowledge and skills needed to survive within the competitive global environment. A detailed analysis of all the learning material of a specific learning programme should lead to the same conclusion.

The key question that this article attempts to answer is whether it is possible for offerings of learning to be relevant to a country specific context of learners and simultaneously prepare learners to be internationally competitive and globally compatible. On a conceptual level one can answer in the affirmative. The two premises of the article are not mutually exclusive. In other words, learning that has occurred in a countryspecific context does not necessarily equip learners with only country-specific knowledge and skills. The problems that are investigated may be countryspecific, but the transferrable knowledge, skills and competencies that are produced from reflection on a problem in one context can be used to solve similar problems in other contexts.

\section{REFERENCES}

Barr, R B \& Tagg, J 1995. From teaching to learning: a new paradigm for undergraduate education. Change: The Magazine of Higher Learning 27(6):12-25 November/December.

Dahlin, B 1999. Ways of coming to understand: metacognitive awareness among first-year university students. Scandinavian Journal of Educational Research 43(2):191-207.

Edwards, R 1997. Changing places? Flexibility, lifelong learning and a learning society. London: Routledge.

Gibbons, M 1998. Higher education relevance in the $21^{\text {st }}$ century. The World Bank Education.

Killen, R \& Spady, W 1999. Using the SAQA critical outcomes to inform curriculum planning in higher education in South Africa. South African Journal of Higher Education 13(2):200-208.

Levinger, B 1996. Human capacity development across the lifespan. Newton, USA: Education Development Centre. Available online at URL: http://www.edc.org/INT/HCD/crittrans.htm.

Marzano, R J, Pickering, D \& McTighe, J 1993. Assessing student outcomes: performance assessment using the dimensions of learning model. Alexandria, Virginia: ASCD.

Melck, A 2000. Speech by Professor A Melck, Principal, Unisa: Closure of the Academic Year, 2000. Online: http://www.unisa.ac.za/about/principal2000.html.

Panel 1999. Results of a qualitative/quantitative assessment of the study guide one of PAD100-X. Department of Public Administration. Pretoria: Unisa.

Schön, D A 1995. The new scholarship requires a new epistemology: knowing-in-action. Change: The Magazine of Higher Learning 27(6):26-39 November/December.

Stewart, P 1999. Development at the dawn of the twenty-first century, in Wessels, J S \& Pauw, J C (eds) Reflective public administration: views from the South. Cape Town: Oxford University Press.

Survey 1998. Results of a survey of students that were enrolled during 1998 at the University of South Africa enrolled for the course PAD100-X.

Theunissen, C A 1999. Interactional Dynamics of Public Administration. Study guide 2 for PUB307-L. Pretoria: University of South Africa.

Vermunt, J D 1996. Metacognitive, cognitive and affective aspects of learning styles and strategies: a phenomenographic analysis. Higher Education 31:25-50

Wessels, J S 2000. Equipping public officials for challenges of responsible governance: a South African perspective on lifelong learning. International Review of Administrative Sciences 66(2):311-324.

Wessels, J S 2001a. Criteria for assessing learning material for distance education. South African Journal of Higher Education 15(1):217-224.

Wessels, J S $2001 \mathrm{~b}$. Assessing learning material for distance education: a case study. Politeia - Journal for the Political Sciences 20(3):forthcoming.

Zuber-Skerritt, O 1993. Improving learning and teaching through action learning and action research. Higher Education Research and Development 12(1):46-57. 